\title{
Experimental Analysis on the Ultrasound-based Mixing Technique Applied to Ultra-low Sulphur Diesel and Bio-oils
}

\author{
Anh Tuan Hoang \#,*, Viet Dung Tran ${ }^{+}$ \\ ${ }^{\#}$ Ho Chi Minh City University of Transport, Ho Chi Minh City, Vietnam \\ Email:: anhtuanhoang1980@gmail.com \\ *Ho Chi Minh City University of Technology (HUTECH), Ho Chi Minh City, Vietnam \\ ${ }^{+}$The Maritime College I, Haiphong, Vietnam
}

\begin{abstract}
Pollution in the maritime field is considered as such a serious problem that scientists, policymakers, and managers are always urged with a desire to find solutions and strategies one way or another to minimize its negative impacts on the environment and the life. Among the effective solutions, the use of fuels with limited-sulfur content or bio-based fuels has been paid much attention to due to their advantages in the use of marine diesel engines. In the current study, a type of fossil diesel fuel with ultra-low sulfur content (ULSD) was mixed with coconut oil (CO) through the ultrasonic treatment under the changes in volume fraction of as-used fuels, the correlation on viscosity selected the rate mixing between ULSD and coconut oil. After 12 minutes of ultrasound treatment, the highest stability of the ULSD-CO emulsion was achieved correspondingly to $97.8 \%$ for a mixing rate of 76\%(ULSD):24\%(CO) along with the distance of $85 \mathrm{~mm}$ from the containing-vessel bottom to the ultrasound horn tip. Moreover, the spray characteristics including penetration length and a cone angle of ULSD, CO, and ULSD-CO emulsion were also examined and compared to diesel fuel. The similarity of spray characteristics to diesel fuel, containing ultra-low sulfur content and oxygen content, renewability are considered as some advantages of ULSD-CO emulsion as used for diesel engines aiming to meet the stricter requirements of IMO regulations about the strategies of environmental protection.
\end{abstract}

Keywords_ULSD; coconut oil; ultrasonic treatment; spray characteristics; physical properties.

\section{INTRODUCTION}

The environment is being seriously polluted due to several various sources, but the main cause resulting in the pollution mentioned above is due to transportation sectors. Facts have shown that the numbers of transportation sectors were increased sharply in contrast to the depletion of fossil fuels [1], [2]. Because of these reasons, two strategies such as finding the renewable energy sources [3] and technical solutions for emission management for the improvement of the effectiveness in the use of energy and the environmental protection are essential [4]. Among emissions emitted into the air from the fossil fuel combustion of diesel engines, sulfur emission (SOx) is a dangerous pollutant and it is complicated to control [5], [6]. In the exhaust line of engines, SOx reacts to water under the appropriate conditions to form sulphuric acid, resulting in negative impacts on materials (corrosion) and environment (acid rain). Therefore, by this way or another, the minimization and limitation of sulfur emissions are compulsory for engine manufacturers, policymakers, and managers responding to the strict requirements concerning emission management. International shipping is being criticized for contributing $5-10 \%$ of global SOx emissions.

The reduction of SOx emissions from ships is a hot topic debated in the meeting of the Environmental Protection Committee (MEPC) of the World Maritime Organization (IMO). The MARPOL 73/78 was adopted by the Protocol to control air pollution from ships, the Annex VI of the International Convention for the Prevention of Pollution from Ships, including article 14 of MARPOL Annex VI regulations on reducing emissions of SOx and PM, gases harmful to the environment and human health. The regulation on sulfur content in fuel drops to $0.0015 \%$ when the vessel operates in the SOx emission control area (SECA) effective January 1, 2015 [7]. Most notably, the regulation on maximum sulfur content in fuel is $0.05 \%$ applied worldwide from January 1, 2020. There are many suggested solution to reduce SOx emissions in maritime such as the injection process management, improvement of the fuel supply system, using low sulfur fuels [8], [9]. However, low sulfur fuel use may be appropriate to existing diesel engines. 
To implement air pollution control regulations, it is required that activities in SECA must use ULSD. The integration of a chiller in the ULSD fuel supply system is proposed by the engine manufacturers and the propulsion system design department to improve ULSD's disadvantages such as low viscosity and low density, although the initial cost for the investigation of this cooling system is normally very high. Furthermore, vegetable oils (VO) with regenerative, renewable, biodegradable, and non-toxic properties are recommended for marine diesel engines to promote the "Green transport." It is worth mentioning that VO has a much higher kinematic viscosity $(\mu)$, higher density and lower evaporation compared to DF [10], [11]. Considering in mind, mixing ULSD (low density) and VO (high density) will result in a mixture with suitable physical properties for the use in diesel engines [12].

Compared to VO, well-mixed ULSD-VO has higher storage stability, lower cloud point, higher Cetane number, and heating value [13]. Also, the increase in lubrication, the reduction of friction loss and wear, the reduction of nozzle erosion of ULSD-VO blend in comparison to ULSD may be seen [14]. Hence, in terms of fuel standards used for marine diesel engines, a blend of ULSD and VO should be considered as an effective solution [15], [16].

Improving the mixing efficiency in a micro reactor to create a homogeneous mixture of two separate liquid phases is considered an essential technical solution to ensure fuel quality when converting to fuel with low sulfur content [17]. Among the positive methods, ultrasonic mixing technique is considered a non-contact method to create micro and homogeneous structures with very high efficiency [18]. The superior advantages of ultrasonic technology in the blending of multi-phase currents, because the sound stream, local hot spots are created and the formation of the jet is formed at the average compartments of liquid-liquid phase to create cavity-based bubbles [19], [20], resulting in the implosion of the cavitation-based bubbles by shockwaves [21]. Therefore, the two impregnable liquid-liquid phases affected by ultrasound lead to breakage to create an emulsion [22]-[24]. The ultrasonic technique is used to produce the emulsion of water-diesel fuel [25], [26], the combustion properties of water-diesel fuel emulsion from this experimental work were indicated to be better compared to DF. In the study of Imazu et al. [27], they have reported the good stability of emulsion generated by diesel-water-vegetable oils after ultrasound treatment. Additionally, ultrasonic methods were employed in several other studies about the preparation of emulsions for bio-based fuels and low-viscosity fuels [28]-[30].

This current work aims to produce the emulsion of ULSD and VO based on the assistance of the ultrasonic technique. Some physical properties of ULSD-VO emulsion including viscosity, density, and surface tension as well as cetane number were determined. Moreover, spray characteristics of ULSD-VO emulsion after being created by the ultrasound are also tested and compared to DF, VO, and ULSD. The obtained results allow carrying out experiments on the use of ULSD-VO emulsion for diesel engines as an alternative fuel to evaluate the sulfur emissions.

\section{MATERIALS AND METHODS}

\section{A. Materials}

To prepare the blend for ultrasound treatment, coconut oil (CO) and ultra-low sulfur diesel (ULSD) with $0.001 \%$ mass of sulfur were used. Properties of a blend of ULSD and CO after ultrasound treatment were compared to properties of fossil diesel fuel (DF) (diesel fuel No.2 with $0.25 \%$ of sulfur and DF is commonly used for diesel engines in transport sectors, forestry and agricultural fields, and generator sets). ULSD and DF were purchased from The Vietnam National Petroleum Group (Petrolimex). CO is the available vegetable oil in the South, Vietnam. The properties of CO, ULSD, and DF were presented in Table 1.

TABLE I

PROPERTIES OF CO, ULSD, AND DF AT ROOM TEMPERATURE

\begin{tabular}{|l|c|c|r|r|}
\hline \multicolumn{1}{|c|}{ Properties } & Unit & CO & ULSD & \multicolumn{1}{c|}{ DF } \\
\hline Density, $\rho$ & $\mathrm{g} / \mathrm{ml}$ & 0.9103 & 0.832 & 0.852 \\
\hline Kinematic viscosity, $\mu$ & $\mathrm{cSt}$ & 28.1 & 1.9 & 3.6 \\
\hline Surface tension, $\sigma$ & $\mathrm{mN} / \mathrm{m}$ & 0.034 & 0.0244 & 0.0252 \\
\hline Sulfur content & $\mathrm{ppm}$ & 170 & 10 & 2500 \\
\hline Cetane number, $\mathrm{CN}$ & & 39 & 44 & 45 \\
\hline $\begin{array}{l}\text { Higher heating value, } \\
\text { HHV }\end{array}$ & $\mathrm{kJ} / \mathrm{kg}$ & 38.000 & 42.5000 & 44.000 \\
\hline Flash point, $\mathrm{FP}$ & ${ }^{\circ} \mathrm{C}$ & 200 & 55 & 68 \\
\hline Pour point, $\mathrm{PP}$ & ${ }^{\circ} \mathrm{C}$ & 12 & -18 & -13 \\
\hline Cloud point, $\mathrm{CP}$ & ${ }^{\circ} \mathrm{C}$ & 21 & -6 & -3 \\
\hline
\end{tabular}

From Table 1 that $\mathrm{HHV}$ and $\mathrm{CN}$ of $\mathrm{CO}$ are respectively $16 \%$ and $13 \%$ smaller compared to DF. These results show that it is more difficult to burn $\mathrm{CO}$ completely in diesel engines. Density $(\rho)$, kinematic viscosity $(\mu)$, surface tension $(\sigma)$ of CO are much higher than those of DF. Therefore, it is necessary to improve CO's triple physical properties. Also, Table 1 shows that these triple physical properties of ULSD are lower than those of DO. However, the sulfur content of $\mathrm{CO}$ and ULSD is much lower than that of DF. Mixing CO and ULSD can lead to the blend with density, viscosity, surface tension equal to those of DF.

\section{B. Methods}

A method assisted by ultrasonic technique through cavitation mechanism resulting in bursting the bubbles to form the homogeneous blends was used in this work to mix $\mathrm{CO}$ and ULSD. The mixing rate between CO and ULSD may be determined versus kinematic viscosity $(\mu)$ and density $(\rho)$ by following Eq. 1 and Eq. 2 [31].

$$
\begin{gathered}
\ln \mu=x_{1} \ln \mu_{1}+x_{2} \ln \mu_{2}+\ldots+x_{n} \ln \mu_{n} \\
\rho=x_{1} \rho_{1}+x_{2} \rho_{2}+\ldots+x_{n} \rho_{n}
\end{gathered}
$$

Where: $\mu_{i}$ is kinematic viscosity of component $\mathrm{i}, \mathrm{cSt}$; $\rho_{\mathrm{i}}$ is the density of component $\mathrm{i}, \mathrm{g} / \mathrm{ml} ; \mathrm{X}_{\mathrm{i}}$ is the volume percentage of component $i(\%)$.

The selection of Eq. 1 and Eq. 2 for the determination of the mixing rate between ULSD and $\mathrm{CO}$ was because viscosity and density were two key parameters, which must satisfy the requirements and standards related to fuels used for diesel engines. Indeed, each $2 \%$ of $\mathrm{CO}$ volume 
percentage was mixed with ULSD. After mixing based on ultrasound treatment, the standards such as ASTM D1298 for the density test (by hydrometer with the measuring range from $0.7 \mathrm{~g} / \mathrm{cm}^{3}$ to $1.0 \mathrm{~g} / \mathrm{cm}^{3}$ ), ASTM D 445 for the viscosity test (based on CANNON Viscometer tube with the measuring range from 2 to $30 \mathrm{cSt}$ ), and ASTM D971 for the surface tension test (by Du Nouy ring method) were used for ULSD-CO blend under room temperature of $30^{\circ} \mathrm{C}$ and ambient pressure.

Spray characteristics including penetration and cone angle were examined by the self-built system that was mounted with a high-speed camera. Ultrasound-assisted ULSD-CO blend was poured into the centrifugal separator device that was operated under rotation speed of $2500 \mathrm{rpm}$ during 20 min to test the stability level of ultrasound-assisted ULSD$\mathrm{CO}$ emulsion. After that, the volume of ultrasound-assisted ULSD-CO emulsion after centrifugal separator treatment was determined. The stability level of ULSD-CO emulsion phase (SEP) was calculated through Eq. 3:

$$
S E P=\frac{\mathrm{V}_{-} \mathrm{a}}{\mathrm{V} \_\mathrm{b}} \%
$$

$\mathrm{V} \_a$ : Emulsion volume after centrifugal treatment, $\mathrm{ml}$

V_b: Total sample volume before centrifugal treatment, ml

\section{Experimental setup}

The ultrasound-based blending method of ULSD and CO was illustrated in Fig.1. The ultrasound horn-type was used for the mixing purpose with the frequency ultrasound of 28 $\mathrm{kHz}$ along with the ultrasound input-power of $100 \mathrm{~W}$. Mixing chamber was a cylindrical vessel with a diameter of $100 \mathrm{~mm}$ and the height of $100 \mathrm{~mm}$. The condition for the conduction of mixing ULSD and CO was kept under a temperature of $30^{\circ} \mathrm{C} \pm 1$ and ambient pressure.

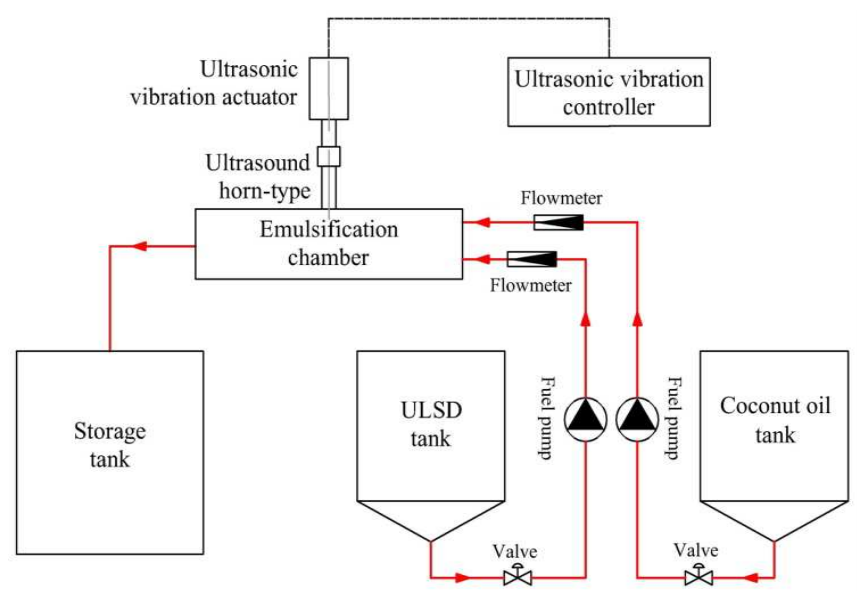

Fig. 1. Mixing principle of ULSD-CO by ultrasound treatment

Fuels of ULSD and CO were stored in the separate tanks; they were transferred to the mixing chamber by the electrical pump. The volume of ULSD and $\mathrm{CO}$ was carefully determined before mixing and was measured by the highlysensitive flow meter. An after-mixing blend of ULSD-CO was driven to the storage tank. Ultrasonic vibration controller adjusted ultrasound frequency and input-power. After finishing the mixing process, physical properties of
ULSD-CO blend, as well as spray characteristics, were experimentally tested. The experimental schema for the characteristic spray test was presented in Fig. 2.

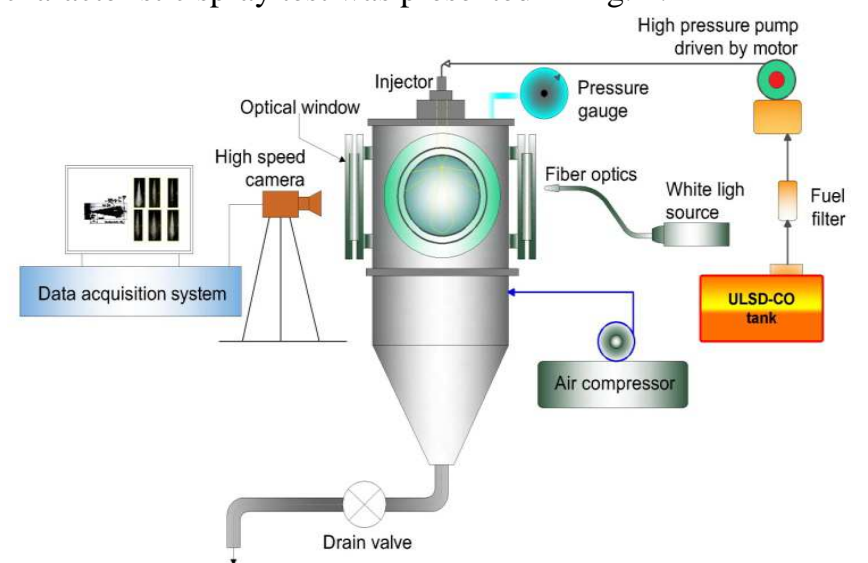

Fig. 2. The experimental schema for the test of ULSD-CO spray characteristics

As illustrated in Fig.2, a mechanical pump was used to provide fuel with the injector that was set at opening pressure of 200bar. The fuel pump in this experiment was driven by a motor and was connected to injector through a high-pressure line. The ULSD-CO blend was delivered into the pump mentioned above from ULSD-CO storage tank. A high-speed camera with technical features of $120 \mathrm{fps}$ for shutter speed and resolution of 18 megapixels was used to take photos of spray characteristics as located orthogonally with the optical window and spray direction.

\section{RESULTS AND DISCUSSIONS}

\section{A. Mixing rate between ULSD and CO}

The selection of the mixing rate based on the volume percentage between ULSD and CO was determined versus Eq.1 and Eq. 2. Achieved results concerning kinematic viscosity $(\mu)$ and density $(\rho)$ of ULSD-CO blend under the changes in the volume percentage were given in Table 2.

TABLE II

KINEMATIC VISCOSITY AND DENSITY OF ULSD-CO BLEND BASED ON EQ.1 AND EQ.2 AT ROOM TEMPERATURE

\begin{tabular}{|c|c|c|c|}
\hline Fuel type & CO fraction (\%) & ULSD fraction (\%) & $\begin{array}{c}\text { Kinematic } \\
\text { viscosity, cSt }\end{array}$ \\
\hline \multirow{12}{*}{ ULSD-CO } & 2 & 98 & 2.005 \\
\hline & 4 & 96 & 2.116 \\
\hline & 6 & 94 & 2.233 \\
\hline & 8 & 92 & 2.357 \\
\hline & 10 & 90 & 2.487 \\
\hline & 12 & 88 & 2.625 \\
\hline & 14 & 86 & 2.770 \\
\hline & 16 & 84 & 2.924 \\
\hline & 18 & 82 & 3.086 \\
\hline & 20 & 80 & 3.256 \\
\hline & 22 & 78 & 3.437 \\
\hline & 24 & 76 & 3.627 \\
\hline Fuel type & CO fraction (\%) & ULSD fraction (\%) & Density, g/ml \\
\hline \multirow{8}{*}{ ULSD-CO } & 2 & 98 & 0.834 \\
\hline & 4 & 96 & 0.835 \\
\hline & 6 & 94 & 0.837 \\
\hline & 8 & 92 & 0.838 \\
\hline & 10 & 90 & 0.840 \\
\hline & 12 & 88 & 0.841 \\
\hline & 14 & 86 & 0.843 \\
\hline & 16 & 84 & 0.845 \\
\hline
\end{tabular}




\begin{tabular}{|c|c|c|c|}
\hline \multirow{3}{*}{} & 18 & 82 & 0.846 \\
\cline { 2 - 4 } & 20 & 80 & 0.848 \\
\cline { 2 - 4 } & 22 & 78 & 0.849 \\
\cline { 2 - 4 } & 24 & 76 & 0.851 \\
\hline
\end{tabular}

It can be observed from Table 2 that kinematic viscosity $(\mu)$ and density $(\rho)$ of ULSD-CO blend with $76 \%$ of ULSD and $24 \%$ of CO was respectively $3.627 \mathrm{cSt}$ and $0.851 \mathrm{~g} / \mathrm{ml}$ compared to $3.6 \mathrm{cSt}$ and $0.852 \mathrm{~g} / \mathrm{ml}$ of $\mathrm{DF}$ at room temperature $\left(30^{\circ} \mathrm{C}\right)$. Although this kinematic viscosity $(\mu)$ and density $(\rho)$ of ULSD-CO blend were still $0.75 \%$ and $0.12 \%$ higher compared to DF, those errors were lower than $5 \%$. Therefore, the suitable rate for mixing ULSD and $\mathrm{CO}$ may be selected $76 \%$ (ULSD):24\%(CO). The ultrasound assistance mixed the above blend of $76 \%: 24 \%$ rate for ULSD and $\mathrm{CO}$ before conducting the next evaluation.

\section{B. Effect of ultrasound-horn tip position on the SEP of ULSD-CO blend}

The position of the ultrasound horn tip was thought to affect strongly the level and the speed as well as the SEP of the formation of ULSD-CO blend by ultrasound treatment. The correlation of the position of the ultrasound horn tip in the mixing chamber and the SEP of ULSD-CO blend in case of $76 \%: 24 \%$ rate for ULSD-CO after $12 \mathrm{~min}$ of ultrasonic treatment was drawn in Fig.3.

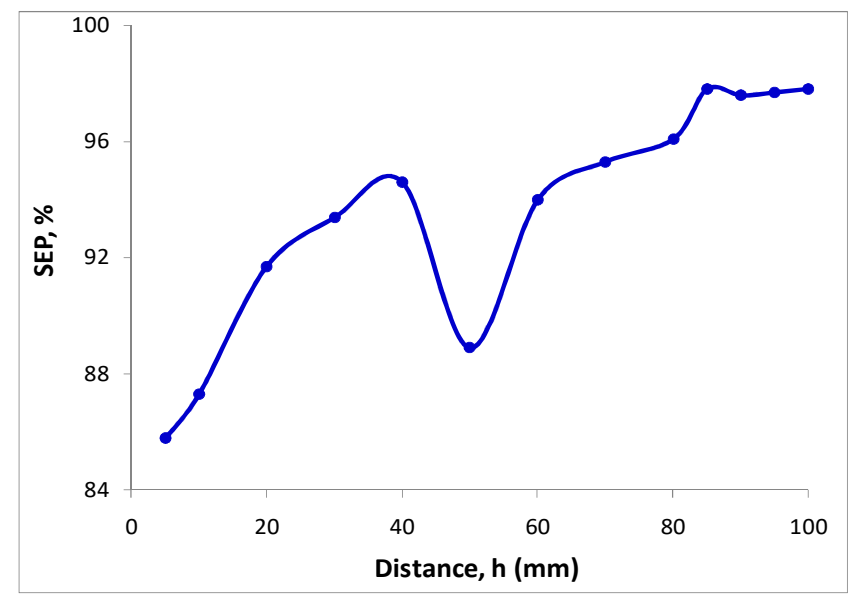

Fig. 3. Effects of the distance h (mm) on the SEP (\%)

Herein, $\mathrm{h}(\mathrm{mm})$ is the distance from the ultrasonic horn tip to the bottom of the mixing vessel. It can be seen from Fig. Three that the lowest SEP of ULSD-CO blend was only $85.8 \%$ in case of $\mathrm{h}=5 \mathrm{~mm}$, the fluctuating trend of the change in SEP with the dependence on distance $h(\mathrm{~mm})$ can be illustrated in Fig.3. Also, it can be seen that the highest SEP was $97.8 \%$ with $\mathrm{h}=85 \mathrm{~mm}$, this SEP was insignificantly changed as increasing distance $h$. For small values of distance $\mathrm{h}(\mathrm{h}=5-40 \mathrm{~mm})$, the initial disturbance due to molecular of both ULSD and CO occurred because the turbulence of ultrasound has broken the structure of ULSD and $\mathrm{CO}$, resulting in the increase in homogeneity between ULSD and CO. As a result, the increase in SEP has reflected that homogeneity of ULSD and CO. However, the reducing tendency for SEP at a distance $\mathrm{h}=50 \mathrm{~mm}$ can also be seen, the reason for the explanation of the above reduction for SEP may be due to the steric obstruction or the minimum of wave interference that is caused by the significant immersion of ultrasound horn tip in mixing vessel. There are two existing mechanisms to explain the formation (increase SEP) and breaking (reduce SEP) structure of ULSD-CO blend as followed:

- Formation: Bubbles of ULSD and CO produced by the cavitation mechanism, bursting those bubbles leads to form the homogeneity of two-phase liquidliquid fuel.

- Breaking: Coalescence of broken bubbles resulting in a decrease in SEP.

In the case of distance $\mathrm{h}=50 \mathrm{~mm}$, the breaking of bubbles of ULSD-CO may win their formation, the phase of ULSD$\mathrm{CO}$ emulsion was thus broken much more than its formation. Nonetheless, as increasing distance $h$ to higher values, the smooth convection currents produced by the acoustic ultrasound streaming has increased SEP, the maximal SEP has achieved at the distance $h$ of $85 \mathrm{~mm}$. The convection currents from the acoustic ultrasound streaming acted as a leading factor; the high efficient formation of ULSD-CO emulsion is considered as a result of the sufficient agitation. In some published studies [25], [27], the similar reports on the effects of horn tip position on the SEP of two liquid fuel types after ultrasound treatment were presented. Additionally, the dependence of SEP and kinematic viscosity $(\mu)$ of ULSD-CO emulsion on the time of the ultrasound treatment process in the case of the distance $h=85 \mathrm{~mm}$ was illustrated in Fig.4.

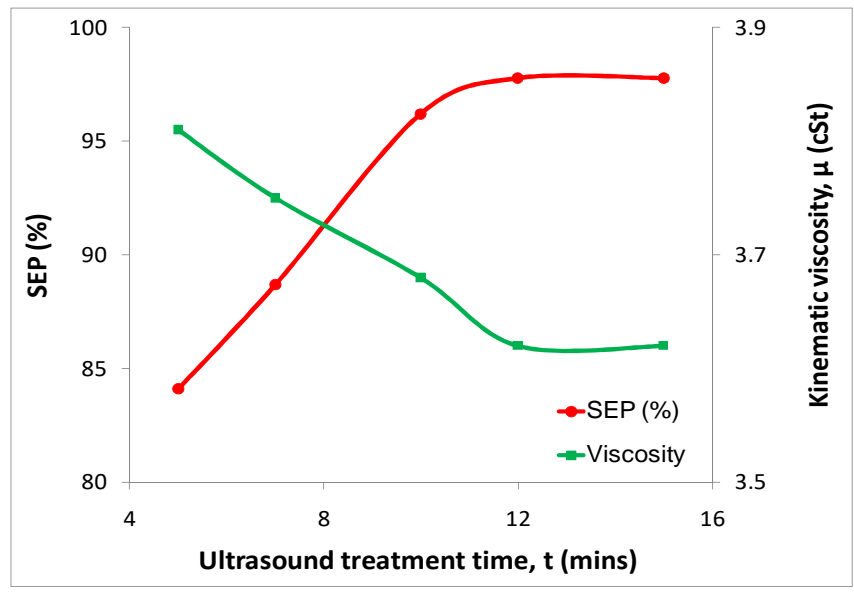

Fig. 4. The dependence of SEP $(\%)$ and kinematic viscosity $(\mu)$ of ULSD$\mathrm{CO}$ emulsion on time $(\mathrm{t})$

Fig. 4 showed that SEP increased sharply within the first ten minutes, and then SEP was unchanged although the ultrasound treatment time increased. Kinematic viscosity $(\mu)$, it showed a reducing tendency when the time of ultrasound treatment increased. These results were suitable for the obtained SEP because the increase in SEP was a result of the homogeneous blend of ULSD-CO, in which there are not any separations between liquid fuel layers. Based on the experimental results, the optimal conditions for ultrasound treatment for ULSD and CO were distance $\mathrm{h}=85 \mathrm{~mm}$, the frequency of $28 \mathrm{kHz}$ with the time for ultrasound treatment of 12 minutes. 


\section{Physical properties of ULSD-CO blend}

After $12 \mathrm{~min}$ of ultrasound treatment, physical properties of ULSD-CO emulsion were measured based on the standards mentioned above and devices. The results of physical properties of ULSD-CO emulsion with 76\%(ULSD):24\%(CO) mixing rate including LHV, CN, FP, PP, CP, density $(\rho)$, kinematic viscosity $(\mu)$ and surface tension $(\sigma)$ were listed in Table 3.

TABLE III

PROPERTIES OF ULSD-CO EMULSION AFTER ULTRASOUND TREATMENT

\begin{tabular}{|l|r|r|r|r|r|}
\hline \multicolumn{1}{|c|}{ Properties } & Unit & \multicolumn{1}{c|}{ CO } & ULSD & $\begin{array}{l}\text { ULSD-CO } \\
\text { emulsion }\end{array}$ & \multicolumn{1}{c|}{ DF } \\
\hline Density, $\rho$ & $\mathrm{g} / \mathrm{ml}$ & $\begin{array}{r}0.910 \\
3\end{array}$ & 0.832 & 0.85 & 0.852 \\
\hline $\begin{array}{l}\text { Kinematic } \\
\text { viscosity, } \mu\end{array}$ & $\mathrm{cSt}$ & 28.1 & 1.9 & 3.62 & 3.6 \\
\hline $\begin{array}{l}\text { Surface tension, } \\
\sigma\end{array}$ & $\begin{array}{c}\mathrm{mN} / \\
\mathrm{m}\end{array}$ & 0.034 & 0.0244 & 0.0255 & 0.0252 \\
\hline Sulfur content & $\mathrm{ppm}$ & 170 & 10 & 51 & 2500 \\
\hline $\begin{array}{l}\text { Cetane number, } \\
\text { CN }\end{array}$ & 39 & 44 & 42 & 45 \\
\hline $\begin{array}{l}\text { Higher heating } \\
\text { value, HHV }\end{array}$ & $\begin{array}{c}\mathrm{kJ} / \mathrm{k} \\
\mathrm{g}\end{array}$ & 38.00 \\
\hline Flash point, $\mathrm{FP}$ & ${ }^{\circ} \mathrm{C}$ & 200 & 42.5000 & 41.000 & 44.000 \\
\hline Pour point, $\mathrm{PP}$ & ${ }^{\circ} \mathrm{C}$ & 12 & -18 & 110 & 68 \\
\hline Cloud point, $\mathrm{CP}$ & ${ }^{\circ} \mathrm{C}$ & 21 & -6 & 2 & -13 \\
\hline
\end{tabular}

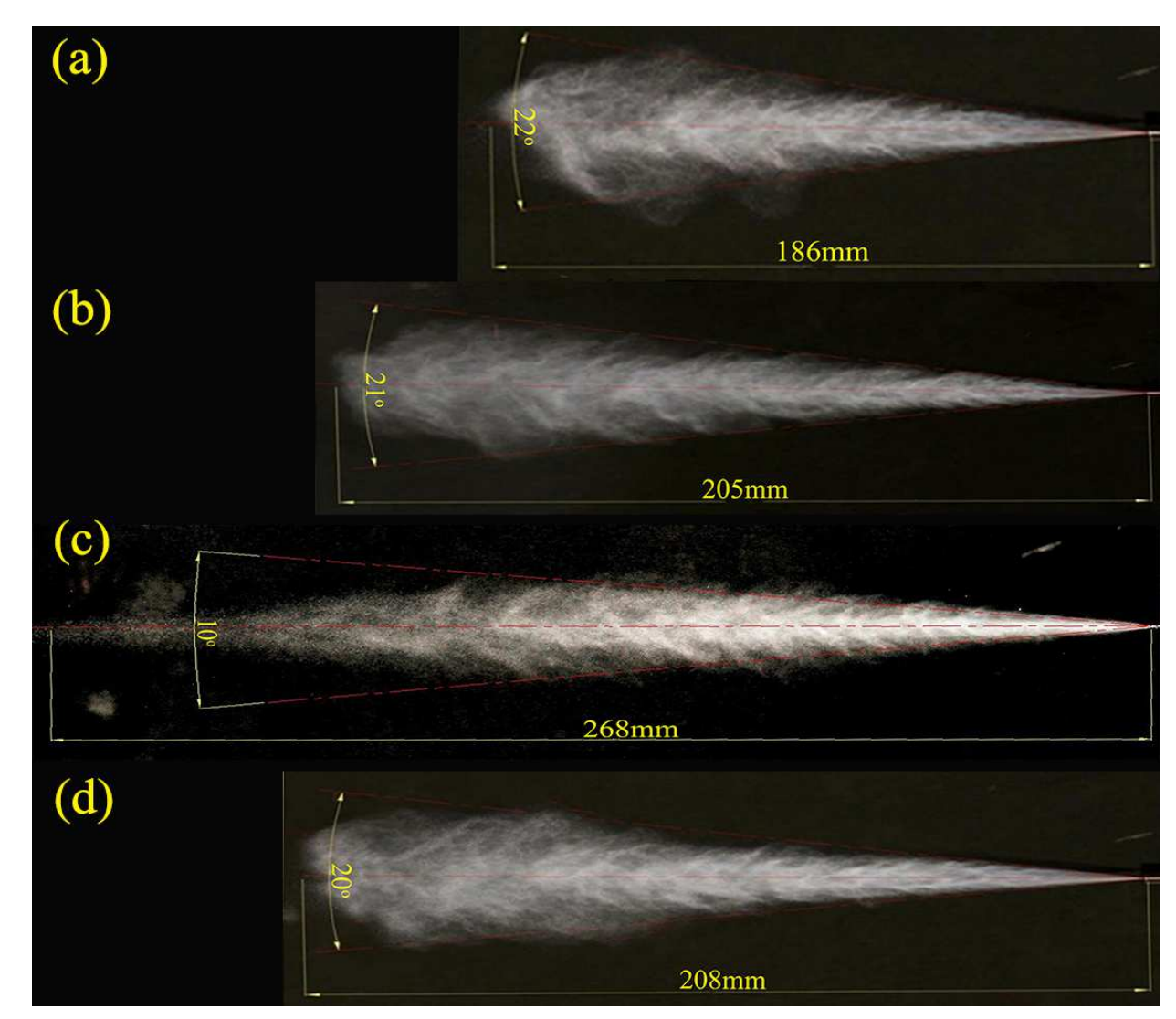

Fig. 5. Spray characteristics of ULSD, CO, DF and ULSD-CO emulsion at room temperature

Spray characteristics of fuels act as the primary parameters in the tight relation to evaporation mixture formation, combustion, and emissions in diesel engines.
Obtained results by experimental measurement from Table 3, some conclusions can be given:

- For 76\%(ULSD):24\%(CO) blend, density $(\rho)$ and kinematic viscosity $(\mu)$ were equal to those of DF, although little errors compared to theoretical calculation such as $0.12 \%$ for density, $0.19 \%$ for kinematic viscosity can be seen. Also, and surface tension $(\sigma)$ was $0.12 \%$ higher than that of DF.

- Sulfur content of 76\%(ULSD):24\%(CO) blend was very small, equal to $51 \mathrm{ppm}$ and compared to $2500 \mathrm{ppm}$ of DF.

- Cetane number $(\mathrm{CN})$ and higher heating value (HHV) of $76 \%$ (ULSD):24\%(CO) blend was respectively $6.67 \%$ and $6.81 \%$ lower than DF. However, $\mathrm{CN}$ and HHV of $76 \%$ (ULSD): $24 \%$ (CO) blend have well satisfied the requirements of fuels used for diesel engines.

- FP, PP, and CP of 76\%(ULSD):24\%(CO) blend was improved. Therefore, the combustion characteristic of $76 \%$ (ULSD): $24 \%$ (CO) blend was much better than CO.

\section{Spray characteristics}

Fig.5 presented the spray characteristics (including penetration length and cone angle) of ULSD, CO, ULSD-CO emulsion in comparison with DF under room conditions. 
parameters $(\mathrm{S}, \mathrm{SMD} / \mathrm{d}$, and $\theta)$, breakup time $\left(\mathrm{t}_{\mathrm{br}}\right)$ and physical fuel properties $(\mu, \rho, \sigma)$ may be presented through following equations [32]:

$$
\begin{gathered}
L_{b}=3.07\left(\frac{\Delta p}{\rho_{g}}\right)^{1 / 4}(t . D)^{1 / 2}\left(\frac{294}{T_{g}}\right)^{1 / 4} \\
\tan \left(\frac{\Phi}{2}\right)=\frac{4 \pi}{3+0.28 \frac{L}{D}}\left(\frac{\rho_{g}}{\rho_{l}}\right)^{1 / 2} \frac{\sqrt{3}}{6}\left(1-\exp \left(-10\left(\frac{\mathrm{Re}_{l}}{W e_{l}}\right)^{2} \frac{\rho_{l}}{\rho_{g}}\right)\right) \\
\frac{S M D}{d}=0.38 \operatorname{Re}_{l}^{1 / 4} W e_{l}^{-0.32}\left(\frac{\mu_{l}}{\mu_{g}}\right)^{0.37}\left(\frac{\rho_{l}}{\rho_{g}}\right)^{-0.47} \\
t_{b r}=\frac{28,65 . \rho_{l} . D}{\left(\rho_{g} \Delta p\right)^{0.5}}
\end{gathered}
$$

Where: $\mathrm{Re}_{\mathrm{l}}, \mathrm{We}_{\mathrm{l}}, \rho_{\mathrm{l}}, \mu_{\mathrm{l}}$ are Reynolds number, Weber number, density, the dynamic viscosity of liquid fuel. $T_{g}, \rho_{g}$, $\mu_{\mathrm{g}}$ are temperature, density, the dynamic viscosity of the gas. $\mathrm{L}$ and $\mathrm{D}$ are the length and diameter of the injector nozzle. $\Delta \mathrm{p}$ is the differential of injection pressure and ambient pressure.

Fuels with higher viscosity and density are thought to be difficult to evaporate, resulting in a heterogeneous mixture of fuel-air with high-concentration of fuel along with bigsize fuel droplets. Due to the short time for mixture formation and the breakup of fuel in diesel engines (around $\mu \mathrm{s})$, fuels with higher viscosity and density cannot turn into vapor completely. As a consequence, incomplete combustion, the loss of power and the increase in pollution emissions may be occurred [33]. Also, longer penetration and smaller cone angle due to higher viscosity and density are the main causes resulting in reducing the total heated area of fuels because of the decrease in heat flux to fuel droplets. As reported, unburnt fuel is considered as the origination of deposits and lubrication oil degradation [34]. Because of those reasons, vegetable oils are suggested not being used for diesel engines in long-term. Therefore, experimental evaluation for fuel spray characteristics aims to determine the suitability for the use in diesel engines.

From Fig.5, it can be observed that the spray characteristics of ULSD (Fig.5a) and CO (Fig.5c) were very different from those of DF. Due to lower viscosity and density of ULSD, penetration length was $19 \mathrm{~mm}$ shorter, but cone angle was $1^{\circ}$ larger compared to DF (Fig. 5b). Facts showed that the use of ULSD might cause some negative impacts on fuel supply system such as the considerable wear and abrasion of the injector, the fast damage of needle due to low lubrication property of ULSD [35]. To overcome this problem, it is suggested using the cooling system or the chiller to cool ULSD to increase its viscosity. On the contrary, spray characteristics of $\mathrm{CO}$ (Fig.5c) showed a longer penetration and a smaller cone angle than those of DF. This is explained due to the much higher viscosity of CO $(28.1 \mathrm{cSt})$ and higher density $\left(910.3 \mathrm{~kg} / \mathrm{m}^{3}\right)$ compared to DF (viscosity of DF is $3.6 \mathrm{cSt}$ and density of DF is $852 \mathrm{~kg} / \mathrm{m}^{3}$ ).

As a consequence, the penetration length of $\mathrm{CO}$ was
$63 \mathrm{~mm}$ greater, and cone angle was $11^{\circ}$ smaller than those of DF. The use of fuels with viscosity, which is lower or higher than a requirement, causes the unpredicted after-effects. However, after mixing ULSD and $\mathrm{CO}$ by ultrasonic technique, physical properties of ULSD-CO were improved. This was demonstrated through the achieved results in relation to the similarity of both physical properties and spray characteristics of ULSD-CO emulsion in comparison to DF. Fig 5d showed the infinitesimal difference between ULSO-CO and DF, the difference of penetration length and cone angle was around $1.5 \%$. Namely, spray penetration of ULSD-CO emulsion was $208 \mathrm{~mm}$ (compared to $205 \mathrm{~mm}$ of $\mathrm{DF}$ ), and the cone angle of ULSD-CO was $20^{\circ}$ (compared to $21^{\circ}$ of DF). Thorough observation from Fig. $5 \mathrm{~d}$ can indicate that easy evaporation of ULSD-CO emulsion after ultrasound treatment was the same as DF.

\section{CONCLUSIONS}

A novel mixing-method based on the assistance of ultrasonic technique between immiscible two fuel-types such as ULSD and CO was experimentally conducted. Selected two fuel types have ultra-low content of sulfur, but ULSD has extremely low viscosity, and CO has very high viscosity. The optimal mixing rate of ULSD and CO was found with $76 \%$ of ULSD and $24 \%$ of CO. Related to technical parameters of ultrasound treatment, ultrasound frequency of $28 \mathrm{kHz}$ along with ultrasound power of $100 \mathrm{~W}$, and the distance from the ultrasound horn tip to the mixing vessel bottom of $85 \mathrm{~mm}$ and the time for ultrasound treatment of 12 minutes were detected as the optimal conditions. Under the above-mentioned conditions, the stability of ULSD-CO emulsion (SEP) reached 97.8\%. Spray parameters of ULSD$\mathrm{CO}$ were significantly improved compared to ULSD and CO; its spray characteristics including penetration length and cone angle were equal to DF. However, ULSD-CO emulsion contained minimal sulfur content (the only 51ppm compared to 2500ppm in DF). In summary, the application of mixing method by ultrasound to produce the homogeneous blend of liquid fuels may be considered to satisfy the strict strategies on SOx emission management.

\section{NOMENCLATURE}

SMD Sauter mean diameter

$\mathrm{L}_{\mathrm{b}} \quad$ penetration length

L length of injector nozzle

D diameter of injector nozzle

$\mathrm{d}_{\mathrm{p}} \quad$ fuel droplet diameter

u fuel velocity

$\mu \mathrm{m}$

$\mathrm{mm}$

$\mathrm{mm}$

$\mathrm{mm}$

$\mu \mathrm{m}$ $\mathrm{m} / \mathrm{s}$

Greek letters

$\mu \quad$ kinematic viscosity $\mathrm{mm} 2 / \mathrm{s}$

$\rho$ density kg.m-3

$\sigma \quad$ surface tension $\quad \mathrm{mN} / \mathrm{m}$

$\theta$ cone angle degree

\section{REFERENCES}

[1] A. T. Hoang, Q. V. Tran, A. R. M. S. Al-Tawaha, V. V. Pham, and X. $\mathrm{P}$. Nguyen, "Comparative analysis on performance and emission characteristics of an in-Vietnam popular 4-stroke motorcycle engine running on biogasoline and mineral gasoline," Renew. Energy Focus, vol. 28 , pp. 47-55, 2019. 
[2] F. Zhao et al., "Numerical study of soot particles from lowtemperature combustion of the engine fueled with diesel fuel and unsaturation biodiesel fuels," Appl. Energy, vol. 211, pp. 187-193, 2018.

[3] A. T. Hoang and D. C. Nguyen, "Properties of DMF-fossil gasoline RON95 blends in the consideration as the alternative fuel," Int. J. Adv. Sci. Eng. Inf. Technol., vol. 8, no. 6, pp. 2555-2560, 2018.

[4] A. T. Hoang, "Waste heat recovery from diesel engines based on Organic Rankine Cycle," Appl. Energy, vol. 231, pp. 138-166, 2018.

[5] A. T. Hoang, "Prediction of the density and viscosity of biodiesel and the influence of biodiesel properties on a diesel engine fuel supply system," J. Mar. Eng. Technol., 2018.

[6] R. El Geneidy, K. Otto, P. Ahtila, P. Kujala, K. Sillanpää, and T. Mäki-Jouppila, "Increasing energy efficiency in passenger ships by novel energy conservation measures," J. Mar. Eng. Technol., vol. 17, no. 2, pp. 85-98, 2018.

[7] A. T. Hoang and V. V. Pham, "A review on fuels used for marine diesel engines," J. Mech. Eng. Res. Dev., vol. 41, no. 4, pp. 22-32, 2018.

[8] B.-H. Lin, B.-X. Shen, and J.-G. Zhao, "A study on the prediction model for the lubricity of hydrogenated ultra-low sulfur diesel fuel," Energy Sources, Part A Recover. Util. Environ. Eff., vol. 33, no. 3, pp. 254-264, 2010.

[9] A. T. Hoang and A. T. Le, "A review on deposit formation in the injector of diesel engines running on biodiesel," Energy Sources, Part A Recover. Util. Environ. Eff., vol. 41, no. 5, pp. 584-599, 2019.

[10] G.-G. Choi, S.-J. Oh, and J.-S. Kim, "Non-catalytic pyrolysis of scrap tires using a newly developed two-stage pyrolyzer for the production of a pyrolysis oil with a low sulfur content," Appl. Energy, vol. 170, pp. 140-147, 2016.

[11] J. Hwang, C. Bae, C. Patel, R. A. Agarwal, T. Gupta, and A. K. Agarwal, "Investigations on air-fuel mixing and flame characteristics of biodiesel fuels for diesel engine application," Appl. Energy, vol. 206, pp. 1203-1213, 2017.

[12] A. T. Hoang and V. V. Pham, "A study of emission characteristic, deposits, and lubrication oil degradation of a diesel engine running on preheated vegetable oil and diesel oil," Energy Sources, Part A Recover. Util. Environ. Eff., vol. 41, no. 5, pp. 611-625, 2019.

[13] A. T. Hoang, A. T. Le, and V. V. Pham, "A core correlation of spray characteristics, deposit formation, and combustion of a high-speed diesel engine fueled with Jatropha oil and diesel fuel," Fuel, vol. 244, pp. 159-175, 2019.

[14] K. Keynejad, M. Nikazar, and B. Dabir, "Diesel desulfurization using an ultrasound-assisted oxidative process," Pet. Sci. Technol., vol. 36, no. 11, pp. $718-725,2018$.

[15] A. T. Hoang and M. T. Pham, "Influences of heating temperatures on physical properties, spray characteristics of bio-oils and fuel supply system of a conventional diesel engine," Int. J. Adv. Sci. Eng. Inf. Technol., vol. 8, no. 5, pp. 2231-2240, 2018.

[16] L. Tang, H. Fan, J. Guo, W. Zeng, and X. Tao, "Investigation on the mechanism of coal desulfurization by ultrasonic with peroxyacetic acid," Energy Sources, Part A Recover. Util. Environ. Eff., pp. 1-11, 2018.

[17] V. Hessel, H. Löwe, and F. Schönfeld, "Micromixers-a review on passive and active mixing principles," Chem. Eng. Sci., vol. 60, no. 8-9, pp. 2479-2501, 2005.

[18] H. Katou, R. Miyake, and T. Terayama, "Non-contact micro-liquid mixing method using ultrasound," JSME Int. J. Ser. B Fluids Therm. Eng., vol. 48, no. 2, pp. 350-355, 2005.

[19] S. Aljbour, T. Tagawa, and H. Yamada, "Ultrasound-assisted capillary microreactor for aqueous-organic multiphase reactions," $J$.
Ind. Eng. Chem., vol. 15, no. 6, pp. 829-834, 2009.

[20] S. Hübner et al., "Ultrasound and microstructures-a promising combination?," ChemSusChem, vol. 5, no. 2, pp. 279-288, 2012.

[21] I. Korkut and M. Bayramoglu, "Various aspects of the ultrasoundassisted emulsion polymerization process," Ultrason. Sonochem., vol. 21, no. 4, pp. 1592-1599, 2014.

[22] D. F. Rivas, P. Cintas, and H. J. G. E. Gardeniers, "Merging microfluidics and sonochemistry: towards a greener and more efficient micro-sono-reactors," Chem. Commun., vol. 48, no. 89, pp. 10935-10947, 2012.

[23] M. Mostafaei, H. Javadikia, and L. Naderloo, "Modeling the effects of ultrasound power and reactor dimension on the biodiesel production yield: comparison of prediction abilities between response surface methodology (RSM) and adaptive neuro-fuzzy inference system (ANFIS)," Energy, vol. 115, pp. 626-636, 2016.

[24] Q. Wu et al., "Ultrasound-assisted surfactant-enhanced emulsification microextraction for the determination of carbamate pesticides in water samples by high-performance liquid chromatography," J. Chromatogr. A, vol. 1217, no. 11, pp. 1773$1778,2010$.

[25] A. Navickas, E. Puida, A. Bubulis, V. Jurenas, and A. Pauliukas, "Investigation of Oil-Water Ultrasound Emulsifier," $J$. Vibroengineering, vol. 1, pp. 35-38, 2013.

[26] T. V. G. Jinu Joseph John, Simon Kuhn, Leen Braeken, "Ultrasoundassisted liquid-liquid extraction in microchannels-A direct contact method," Chem. Eng. Process. Process Intensif., vol. 102, pp. 37-46, 2016.

[27] H. Imazu and Y. Kojima, "Physical properties and combustion characteristics of emulsion fuels of water/diesel fuel and water/diesel fuel/vegetable oil prepared by ultrasonication," J. Japan Pet. Inst., vol. 56, no. 1, pp. 52-57, 2013.

[28] Cherng-Yuan Lin and Li-Wei Chen, "Comparison of fuel properties and emission characteristics of two- and three-phase emulsions prepared by ultrasonically vibrating and mechanically homogenizing emulsification methods," Fuel, vol. 87, no. 10-11, pp. 2154-2161, 2008.

[29] X. Z. and T. J. Yuping Li, Tiejun Wang, Wei Liang, Chuangzhi Wu, Longlong Ma, Qi Zhang, "Ultrasonic Preparation of Emulsions Derived from Aqueous Bio-oil Fraction and 0\# Diesel and Combustion Characteristics in Diesel Generator," Energy Fuels, vol. 24, no. 3, pp. 1987-1995, 2010.

[30] R. N. and Y. M. C Stavarache, M Vinatoru, "Fatty acids methyl esters from vegetable oil using ultrasonic energy," Ultrason. Sonochem., vol. 12, no. 5, pp. 367-375, 2005.

[31] H. Hamidi et al., "The effect of ultrasonic waves on oil viscosity," Pet. Sci. Technol., vol. 32, no. 19, pp. 2387-2395, 2014.

[32] A. T. Hoang, "Experimental study on spray and emission characteristics of a diesel engine fueled with preheated bio-oils and diesel fuel," Energy, vol. 171, pp. 795-808, 2019.

[33] A. T. Hoang and A. T. Le, "Trilateral correlation of spray characteristics, combustion parameters, and deposit formation in the injector hole of a diesel engine running on preheated Jatropha oil and fossil diesel fuel," Biofuel Res. J., 2019.

[34] A. T. Hoang and V. V. Pham, "Impact of Jatropha Oil on Engine Performance, Emission Characteristics, Deposit Formation, and Lubricating Oil Degradation," Combust. Sci. Technol., 2018.

[35] S. Ushakov, H. Valland, J. B. Nielsen, and E. Hennie, "Effects of high sulfur content in marine fuels on particulate matter emission characteristics," J. Mar. Eng. Technol., vol. 12, no. 3, pp. 30-39, 2013. 